\title{
Appendix: Research Methodology
}

Our research framework is built on the Information Systems investment process studies [12, 13]. We track the impacts of HIT investments throughout its lifecycle in a hospital: from adoption to usage and eventually appropriation. Figure 1 shows our conceptual model.

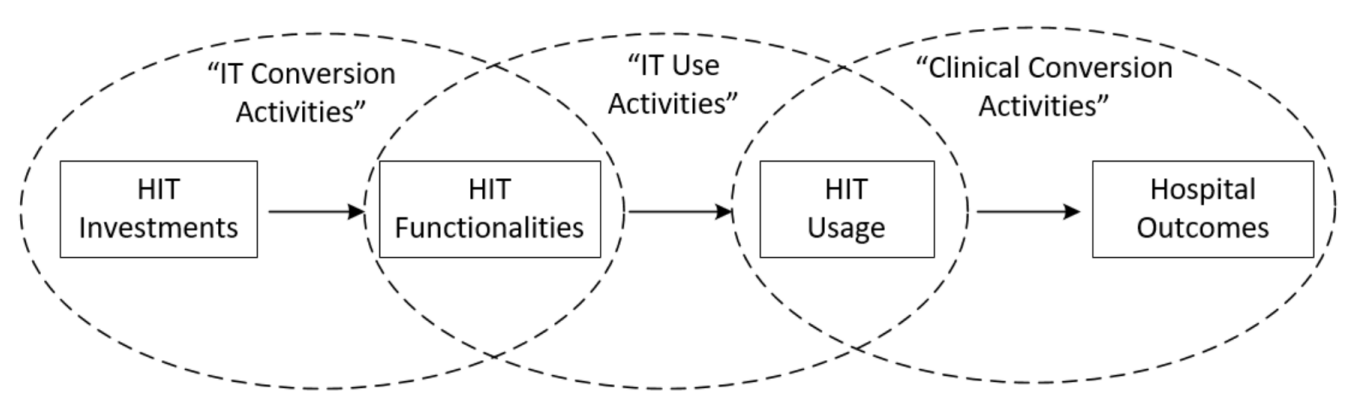

Figure 1: Conceptual Model

Using prior HIT research, we propose our research model in Figure 2. Since most HIT investments focus on EHR systems and HIE participation, we examine the concept of HIT functionalities using the number of implemented EHR functionalities in a hospital and the enabled EMR exchange capabilities. Similarly, we examine the concept of HIT usage as the level of EHR usage in hospital practices and the level of HIE participation. The concept of hospital outcomes is examined using direct and indirect HIT impacts found in the literature: 1) interpersonal care; 2) overall rating; 3) patient loyalty; 4) emergency room (ER) waiting time; 5) readmission rates; and 6) complication rates. Table 1 shows the details of our hypotheses.

To account for other influences on HIT impacts, we include a robust set of controls in the research model. Previous studies have consistently shown that hospital size, nature of the market served (rural vs. urban), and ownership type of a hospital have strong influence the relationship between HIT and hospital outcomes [1]. Thus, we include them in our model. 


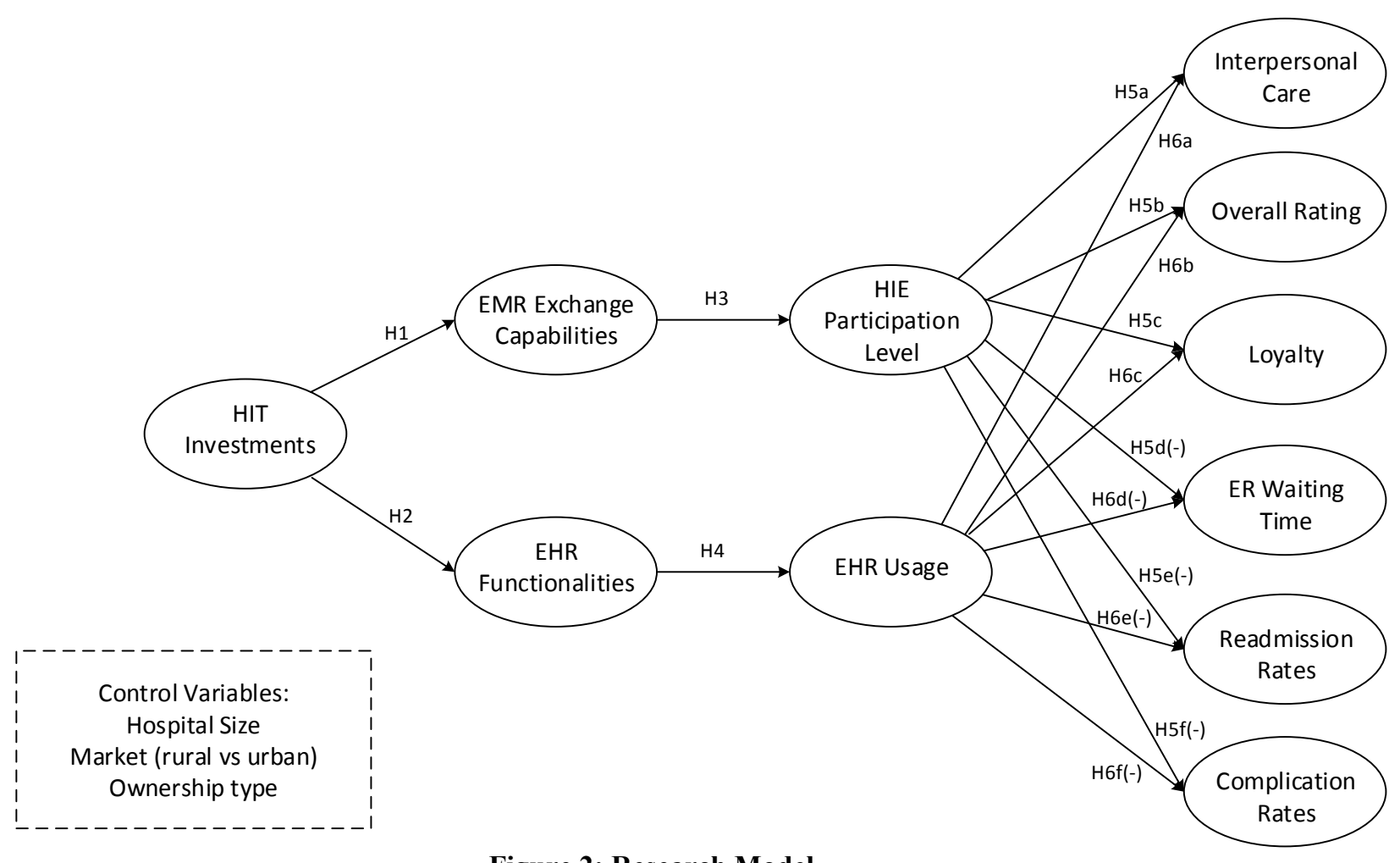

Figure 2: Research Model

Table 1: Proposed Hypotheses

\begin{tabular}{|l|l|}
\hline Hypotheses & References \\
\hline $\begin{array}{l}\text { H1: Higher HIT investments is associated with higher number of enabled EMR exchange } \\
\text { capabilities }\end{array}$ & HITECH Act \\
functionalities & {$[11]$} \\
\hline $\begin{array}{l}\text { H3: Higher number of enabled EMR exchanged capabilities is associated with higher level of } \\
\text { participation in HIE }\end{array}$ & {$[11]$} \\
\hline $\begin{array}{l}\text { H4: Higher number of implemented EHR functionalities is associated with higher level of EHR } \\
\text { usage in healthcare practices }\end{array}$ & {$[12]$} \\
\hline $\begin{array}{l}\text { H5a: Higher level of participation in HIE is associated with increased interpersonal care } \\
\text { H5b: Higher level of participation in HIE is associated with increased overall satisfaction }\end{array}$ & {$[6]$} \\
\hline $\begin{array}{l}\text { H5c: Higher level of participation in HIE is associated with increased patient loyalty } \\
\text { H5d: Higher level of participation in HIE is associated with reduced emergency room waiting }\end{array}$ & {$[6]$} \\
\hline H5e: Higher level of participation in HIE is associated with reduced patient readmission rates & {$[11]$} \\
\hline $\begin{array}{l}\text { H5f: Higher level of participation in HIE is associated with reduced patient complication rates } \\
\text { H6a: Higher level of EHR usage in healthcare practices is associated with increased }\end{array}$ & {$[2]$} \\
\hline interpersonal care & {$[1]$} \\
\hline
\end{tabular}




\begin{tabular}{|l|l|}
\hline $\begin{array}{l}\text { H6b: Higher level of EHR usage in healthcare practices is associated with increased overall } \\
\text { satisfaction }\end{array}$ & {$[1]$} \\
\hline $\begin{array}{l}\text { H6c: Higher level of EHR usage in healthcare practices is associated with increased patient } \\
\text { loyalty }\end{array}$ & {$[1]$} \\
\hline $\begin{array}{l}\text { H6d: Higher level of EHR usage in healthcare practices is associated with reduced emergency } \\
\text { room waiting time }\end{array}$ & {$[16]$} \\
\hline $\begin{array}{l}\text { H6e: Higher level of EHR usage in healthcare practices is associated with reduced patient } \\
\text { readmission rates }\end{array}$ & {$[3,9]$} \\
\hline $\begin{array}{l}\text { H6f: Higher level of EHR usage in healthcare practices is associated with reduced patient } \\
\text { complication rates }\end{array}$ & {$[3]$} \\
\hline
\end{tabular}

We tested the research hypotheses using two datasets obtained from the American Hospital Association (AHA) and Centers for Medicare \& Medicaid Services (CMS) database. The two datasets were merged using the unique hospital Medicare ID number. These datasets characterize the level of HIT implementation and different hospital outcomes respectively in 184 New York hospitals in 2014-2015. The analysis was conducted using SmartPLS [10]. We chose to use SmartPLS because of the complexity of the research model which also contains a mixed of categorical and scale variables; the exploratory nature of our research; and the potential non-normal distribution of our data.

Table 2 lists all measures for this study as well as their source. Because the datasets were designed for healthcare professionals, final datasets were reported with inconsistent scales that require data transformation. For example, the interpersonal care construct was measured using four scale: always, usually, sometimes, and never. However, in the dataset, the respondent rates for "sometimes" and "never" answers were combined. Thus, we used a consistent transformation scheme for those questions as outlined in Table 2.

Table 2: Measured Used in the Study

\begin{tabular}{|l|l|l|}
\hline Variable & Measures & Source \\
\hline Theoretical Constructs: Independent Variables & AHA Dataset \\
\hline HIT investments & Natural log of operating expense & \\
\hline Enabled EMR & Measured by the capabilities to electronically exchange the following & AHA Dataset \\
capabilities & types of document: & \\
& 1. Patient demographics & \\
& 2. Lab results & \\
& 4. Medication history & \\
& 5. Clinical/summary care record in any format & \\
\hline
\end{tabular}




\begin{tabular}{|c|c|c|}
\hline & $\begin{array}{l}\text { Entities available for electronically exchange include: } \\
\text { 1. Hospitals inside the system } \\
\text { 2. Hospitals outside the system } \\
\text { 3. Ambulatory providers inside the system } \\
\text { 4. Ambulatory providers outside the system } \\
\text { The total number of all documents that a hospital can electronically } \\
\text { exchange indicate its capability for EMR exchange. }\end{array}$ & \\
\hline $\begin{array}{l}\text { Implemented EHR } \\
\text { functionalities }\end{array}$ & $\begin{array}{l}\text { Measured by a } 6 \text { points Likert scale of the level of implementation on } \\
\text { six categories of EHR functionalities: } \\
\text { 1. Electronic clinical documentation } \\
\text { 2. Results viewing } \\
\text { 3. Computerized provider order entry } \\
\text { 4. Decision support } \\
\text { 5. Bar coding or RFID } \\
6 . \quad \text { Other functionalities } \\
\text { Eventually, category } \# 5 \text { and } \# 6 \text { were dropped because of low loading }\end{array}$ & AHA Dataset \\
\hline HIE participation level & $\begin{array}{l}\text { A categorical variable that indicate the level of participation with } \\
\text { HIE/HIO: } \\
\text { 1. HIE/HIO is operational, hospital is actively participating and } \\
\text { exchanging data } \\
\text { 2. HIE/HIO is operational, hospital is not participating } \\
\text { 3. HIE/HIO is not operational }\end{array}$ & AHA Dataset \\
\hline EHR usage & $\begin{array}{l}\text { The total number of operational and managerial functions that are } \\
\text { done using clinical data from EHR. The ten possible functions are: } \\
\text { 1. Create a dashboard with measures of organizational } \\
\text { 2. Crformance } \\
\text { 3. Create a dashboard with measures of unit-level performance } \\
\text { 4. Create an approach for clinicians to query the data } \\
\text { 5. Assess adherence to clinical practice guidelines } \\
\text { 6. Identify care gaps for specific patient populations } \\
\text { 7. Generate reports to inform strategic planning } \\
\text { 8. Support a continuous quality improvement process } \\
\text { 9. Monitor patient safety (e.g., adverse drug events) } \\
\text { 10. Identify high risk patients for follow-up care using algorithm } \\
\text { or other tools }\end{array}$ & AHA Dataset \\
\hline \multicolumn{3}{|c|}{ Theoretical Constructs: Hospital Outcomes } \\
\hline Interpersonal care & $\begin{array}{l}\text { Perception of patient toward providers' care using the following } \\
\text { categories: } \\
\text { 1. Doctor communication } \\
\text { 2. Nurse communication } \\
\text { 3. Nurse responsiveness } \\
\text { 4. Instructions before to discharge } \\
\text { The scale for these categories are time scale (Never, Sometimes, } \\
\text { Usually, and Always). However, the dataset reports the aggregate }\end{array}$ & CMS Dataset \\
\hline
\end{tabular}




\begin{tabular}{|c|c|c|}
\hline & $\begin{array}{l}\text { patient percentage that choose a particular answer. For example, } 20 \% \\
\text { choose Sometimes or Never, } 40 \% \text { choose Usually, and } 40 \% \text { choose } \\
\text { Always. Thus, we need to do data transformation for these measures. } \\
\text { The transformation for "interpersonal care" is calculated as below: } \\
\text { Q1=(\%Always*4+\%Usually*3+\%SometimesOrNever*1.5)/100 } \\
\text { Q2=(\%Always*4+\%Usually*3+\%SometimesOrNever*1.5)/100 } \\
\text { Q3=(\%Always*4+\%Usually*3+\%SometimesOrNever*1.5)/100 } \\
\text { Q4=(\%Always*4+\%Usually*3+\%SometimesOrNever*1.5)/100 }\end{array}$ & \\
\hline $\begin{array}{l}\text { Hospital Overall } \\
\text { Rating }\end{array}$ & $\begin{array}{l}\text { An aggregate patient overall rating of a hospital using scale from } 1 \text { - } \\
\text { 10. Follow the transformation procedure of the interpersonal care, the } \\
\text { transformation for overall rating is: } \\
\text { Rating=(\%rating9or } 10 * 9.5+\% \text { rating } 7 \text { or } 8 * 7.5+\% \text { others } * 3) / 100\end{array}$ & CMS Dataset \\
\hline Patient Loyalty & $\begin{array}{l}\text { A question that indicate the aggregate patient perception toward } \\
\text { recommending a hospital. The transformation for the measure is } \\
\text { below: } \\
\text { Loyalty=(\%DefinitelyYes*4+ \%ProbablyYes*3+ } \\
\% \text { ProbablyOrDefinitelyNo*1.5)/100 }\end{array}$ & CMS Dataset \\
\hline ER waiting time & $\begin{array}{l}\text { Average time spent in minutes in the emergency department before } \\
\text { seen by a healthcare professional }\end{array}$ & CMS Dataset \\
\hline Readmission rates & The hospital-wide readmission rates (\%) after discharge from hospital & CMS Dataset \\
\hline Complication rates & A composite complication rates $(\%)$ from various procedures. & CMS Dataset \\
\hline \multicolumn{3}{|l|}{ Control Variables } \\
\hline Hospital size & Natural log of staffed beds & AHA Dataset \\
\hline $\begin{array}{l}\text { Market served (rural } \\
\text { vs. urban) }\end{array}$ & $\begin{array}{l}\text { RUCA code based on hospital's zip code } \\
1=\text { Urban core } \\
2 \text { = Other urban } \\
3 \text { = Large rural core } \\
4=\text { Other large rural } \\
5=\text { Small rural core } \\
6=\text { Other small rural } \\
7=\text { Isolated rural }\end{array}$ & RUCA Dataset \\
\hline Ownership type & $\begin{array}{l}\text { Business orientation and management control of the hospital } \\
1=\text { Government, non-federal } \\
2 \text { = Government, federal } \\
3=\text { Investor, for-profit } \\
4 \text { = Non-government, not-for-profit }\end{array}$ & AHA Dataset \\
\hline
\end{tabular}


A series of tests were conducted to evaluate the measurement reliability (see Table 3) [4]. In our model, there are only two reflective constructs: implemented EHR functionalities and Interpersonal care. Their indicator reliability all exceed the preferable threshold of 0.7 . Their composite validity is satisfactory with the Conbach's alpha over 0.7. Their convergent validity is examined using the Average Variance Extracted (AVE) value. All constructs have AVE value greater than the 0.5 threshold.

Table 3: Reliability Checks

\begin{tabular}{|l|l|c|c|c|c|}
\hline Constructs & Indicators & Loadings & $\begin{array}{c}\text { Indicator reliability } \\
\text { (i.e., loading }\end{array}$ & $\begin{array}{c}\text { Composite } \\
\text { reliability }\end{array}$ & AVE \\
\hline \multirow{4}{*}{$\begin{array}{l}\text { Implemented EHR } \\
\text { functionalities }\end{array}$} & ECD & 0.828 & 0.686 & 0.950 & 0.828 \\
\cline { 2 - 4 } & RV & 0.917 & 0.841 & & \\
\cline { 2 - 4 } & CPOE & 0.963 & 0.927 & & \\
\cline { 2 - 4 } & DS & 0.925 & 0.856 & & \\
\hline Interpersonal Care & Doctor_Comm & 0.925 & 0.856 & & \\
\cline { 2 - 4 } & Nurse_Comm & 0.907 & 0.823 & \\
\cline { 2 - 4 } & Nurse_Resp & 0.872 & 0.760 & \\
\cline { 2 - 4 } & Discharge_Instruction & 0.951 & 0.904 & & \\
\hline
\end{tabular}

Discriminant validity is examined using the correlation table in which the square root of AVE for each construct should be higher than all inter-construct correlation coefficients with the variable and the correlation between pairs of constructs should be below 0.8 [4]. From table 4 below it can be seen that discriminant validity is well established.

Table 4: Fornell-Larcker Criterion Analysis for Checking Discriminant Validity

\begin{tabular}{|l|c|c|c|c|c|c|c|c|c|c|c|}
\hline & 1 & 2 & 3 & 4 & 5 & 6 & 7 & 8 & 9 & 10 & 11 \\
\hline 1. HIT Investments & 1 & & & & & & & & & & \\
\hline 2. EMR Capabilities & 0.13 & 1 & & & & & & & & & \\
\hline 3. EHR Functionalities & 0.172 & 0.302 & 0.91 & & & & & & & & \\
\hline 4. HIE Participation & -0.05 & -0.227 & -0.517 & 1 & & & & & & & \\
\hline 5. EHR Usage & 0.263 & 0.162 & 0.269 & -0.084 & 1 & & & & & & \\
\hline 6. Interpersonal Care & -0.241 & 0.007 & -0.004 & 0.059 & 0.04 & 0.914 & & & & & \\
\hline 7. Overall Rating & -0.145 & 0.035 & 0.017 & 0.048 & 0.04 & 0.896 & 1 & & & & \\
\hline 8. Patient Loyalty & -0.041 & 0.043 & 0.014 & 0.064 & 0.075 & 0.823 & 0.944 & 1 & & & \\
\hline 9. ER Waiting Time & 0.334 & -0.071 & 0.043 & -0.015 & 0.08 & -0.276 & -0.311 & -0.263 & 1 & & \\
\hline 10. Readmission Rates & 0.268 & -0.056 & 0.02 & -0.002 & 0.144 & -0.449 & -0.481 & -0.418 & 0.306 & 1 & \\
\hline 11. Complication Rates & 0.264 & 0.057 & 0.023 & -0.008 & 0.188 & -0.133 & -0.17 & -0.098 & 0.246 & 0.159 & 1 \\
\hline
\end{tabular}

High correlation between factors suggest possible multicollinearity or common method bias [8].

Therefore, a full collinearity test was performed by calculating simulstaneously variance inflation factors (VIFs) in the model [8]. The VIFs for all constructs were less than the recommended threshold of 3.3 by Kock \& Lynn [8] to rule out multicollinearity and common method bias. 
The results of the PLS analysis is shown as below in Figure 4 and Table 5 .

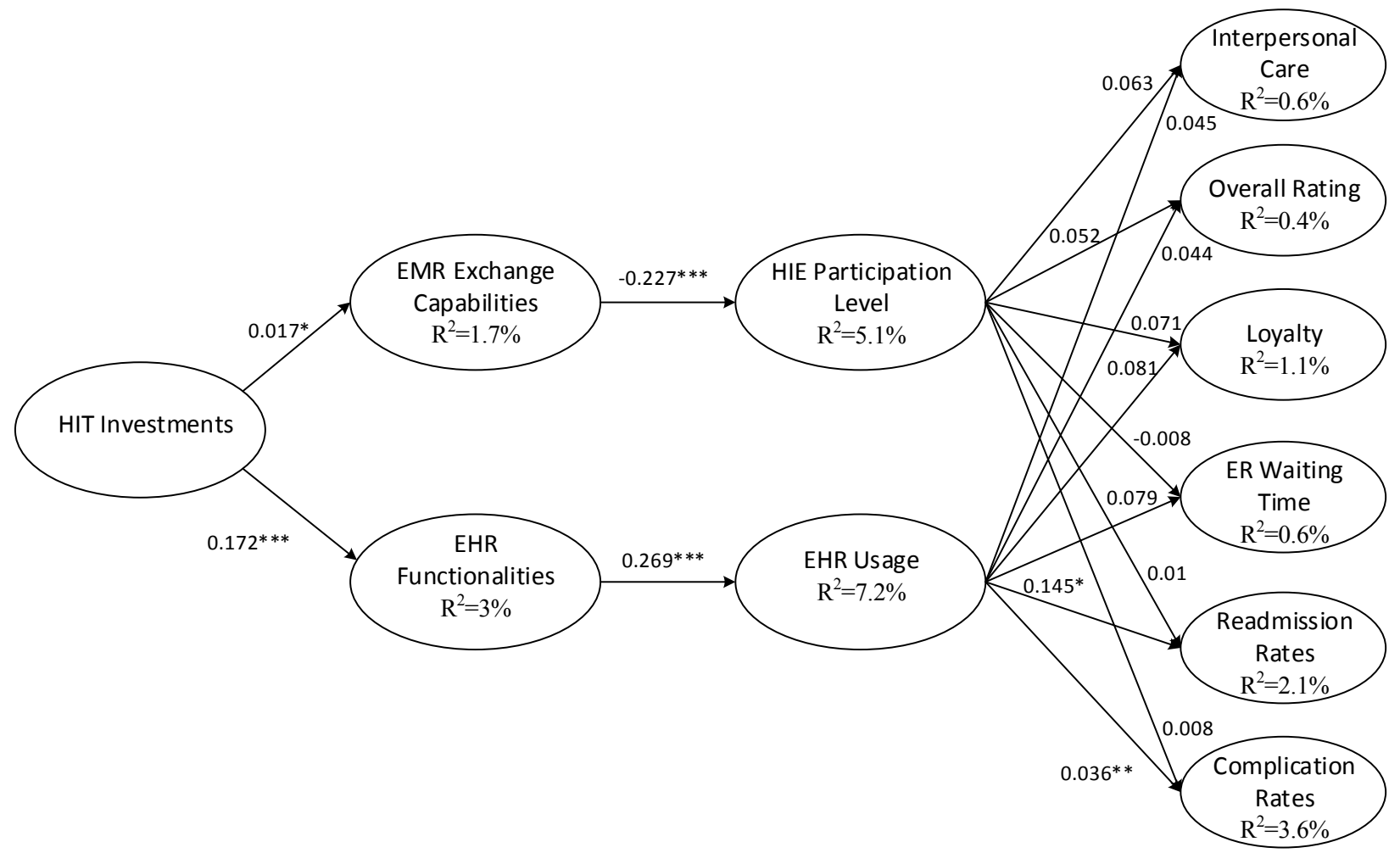

p-value $<0.05 ; * *$ p-value $<0.01 ; * * *$ p-value $<0.001$

Figure 3: PLS model

Table 5: Hypotheses Testing Summary

\begin{tabular}{|l|c|}
\hline Hypotheses & Supported? \\
\hline H1: HIT investments $\rightarrow$ EMR exchange capabilities & Yes \\
\hline H2: HIT investments $\rightarrow$ EHR functionalities & Yes \\
\hline H3: EMR exchanged capabilities $\rightarrow$ HIE participation level & Yes \\
\hline H4: EHR functionalities $\rightarrow$ EHR usage & Yes \\
\hline H5a: HIE participation level $\rightarrow$ Interpersonal care & No \\
\hline H5b: HIE participation level $\rightarrow$ Overall satisfaction & No \\
\hline H5c: HIE participation level $\rightarrow$ Patient loyalty & No \\
\hline H5d: HIE participation level $\rightarrow$ ER waiting time & No \\
\hline H5e: HIE participation level $\rightarrow$ Readmission rates & No \\
\hline H5f: HIE participation level $\rightarrow$ Complication rates & No \\
\hline H6a: EHR usage $\rightarrow$ Interpersonal care & No \\
\hline H6b: EHR usage $\rightarrow$ Overall satisfaction & No \\
\hline H6c: EHR usage $\rightarrow$ Patient loyalty & No \\
\hline H6d: EHR usage $\rightarrow$ ER waiting time & No \\
\hline H6e: EHR usage $\rightarrow$ Readmission rates & Yes (reverse effect) \\
\hline H6f: EHR usage $\rightarrow$ Complication rates & Yes (reverse effect) \\
\hline
\end{tabular}


We include three control variables in our model: hospital size, the nature of market served, and ownership type of the hospital. We first run the base model without control variables, then the full model with the control variables. We then compare the $\mathrm{R}^{2}$ and run the F-test to check whether the difference is significance $[5,15]$. All control variables are significant to the outcome variables.

\section{References}

1. Angst, C.M., Devaraj, S. and D'Arcy, J. Dual Role of IT-Assisted Communication in Patient Care: A Validated Structure-Process-Outcome Framework. Journal of Management Information Systems 29, 2 (2012), 257-292.

2. Ballard, J., Rosenman, M. and Weiner, M., Harnessing a health information exchange to identify surgical device adverse events for urogynecologic mesh. In AMIA Annual Symposium Proceedings, (American Medical Informatics Association 2012.

3. Bardhan, I., Oh, J.H., Zheng, Z.Q. and Kirksey, K. Predictive Analytics for Readmission of Patients with Congestive Heart Failure. Information Systems Research 26, 1 (2015), 19-39.

4. Fornell, C. and Larcker, D.F. Evaluating Structural Equation Models with Unobservable Variables and Measurement Error. Journal of Marketing Research 18, 1 (1981), 39-50.

5. Hair, J.F., Jr., Hult, G.T.M., Ringle, C.M. and Sarstedt, M. A Primer on Partial Least Squares Structural Equation Modeling (PLS-SEM). SAGE Publication, Inc., Thousand Oaks, CA, 2013.

6. Hripcsak, G., Kaushal, R., Johnson, K.B., Ash, J.S., Bates, D.W., Block, R., Frisse, M.E., Kern, L.M., Marchibroda, J. and Overhage, J.M. The United Hospital Fund meeting on evaluating health information exchange. Journal of Biomedical Informatics 40, 6 (2007), S3-S10.

7. Johnson, K.B., Unertl, K.M., Chen, Q., Lorenzi, N.M., Nian, H., Bailey, J. and Frisse, M. Health information exchange usage in emergency departments and clinics: The who, what, and why. Journal of the American Medical Informatics Association 18, 5 (2011), 690-697.

8. Kock, N. and Lynn, G. Lateral collinearity and misleading results in variance-based SEM: An illustration and recommendations. Journal of the Association for Information Systems 13, 7 (2012), 546-580.

9. Menon, N.M. and Kohli, R. Blunting Damocles' Sword: A Longitudinal Model of Healthcare IT Impact on Malpractice Insurance Premium and Quality of Patient Care. Information Systems Research 24, 4 (2013), 918-932.

10. Ringle, C.M., Wende, S. and Will, A. SmartPLS. (2005).

11. Rudin, R.S., Motala, A., Goldzweig, C.L. and Shekelle, P.G. Usage and Effect of Health Information Exchange: A Systematic Review. Annals of Internal Medicine 161, 11 (2014), 803-812.

12. Salge, T.O., Kohli, R. and Barrett, M. Investing in Information Systems: On the Behavioral and Institutional Search Mechanisms Underpinning Hospitals' IS Investment Decisions. MIS Quarterly 39, 1 (2015), 61-89.

13. Soh, C. and Markus, M.L., How IT creates business value: A process theory synthesis. In International Conference on Information Systems (ICIS), (1995.

14. Vest, J.R., Kern, L.M., Silver, M.D., Kaushal, R. and investigators, H. The potential for communitybased health information exchange systems to reduce hospital readmissions. Journal of the American Medical Informatics Association 22, 2 (2014), 435-442.

15. Vinzi, V.E., Chin, W.W., Henseler, J. and Wang, H. Handbook of Partial Least Squares: Concepts, Methods and Applications. Springer, New York, NY, 2010.

16. Yeow, A. and Huat Goh, K. Work Harder or Work Smarter? Information Technology and Resource Allocation in Healthcare Processes. MIS Quarterly 39, 4 (2015), 763-785. 